\title{
TYPE II COLLAGEN-HYALURONAN HYDROGEL - A STEP TOWARDS A SCAFFOLD FOR INTERVERTEBRAL DISC TISSUE ENGINEERING
}

\author{
Laura Calderon $^{1+}$, Estelle Collin ${ }^{1+}$, Diego Velasco-Bayon ${ }^{2}$, Mary Murphy ${ }^{3}$, \\ Damien O’Halloran ${ }^{1}$, and Abhay Pandit ${ }^{1 *}$
${ }^{1}$ Network of Excellence for Functional Biomaterials National University of Ireland, Galway, Ireland
${ }^{2}$ Consejo Superior de Investigaciones Científicas, Madrid, Spain
${ }^{3}$ Regenerative Medicine Institute, National University of Ireland, Galway, Ireland \\ ${ }^{+}$Both authors contributed equally to this paper
}

\begin{abstract}
Intervertebral disc regeneration strategies based on stem cell differentiation in combination with the design of functional scaffolds is an attractive approach towards repairing/regenerating the nucleus pulposus. The specific aim of this study was to optimise a composite hydrogel composed of type II collagen and hyaluronic acid (HA) as a carrier for mesenchymal stem cells. Hydrogel stabilisation was achieved by means of 1-ethyl-3(3-dimethyl aminopropyl) carbodiimide (EDC) and $\mathrm{N}$ hydroxysuccinimide (NHS) cross-linking. Optimal hydrogel properties were determined by investigating different concentrations of EDC ( $8 \mathrm{mM}, 24 \mathrm{mM}$ and $48 \mathrm{mM}$ ). Stable hydrogels were obtained independent of the concentration of carbodiimide used. The hydrogels crosslinked by the lowest concentration of EDC ( $8 \mathrm{mM})$ demonstrated high swelling properties. Additionally, improved proliferation of seeded rat mesenchymal stem cells (rMSCs) and hydrogel stability levels in culture were observed with this $8 \mathrm{mM}$ cross-linked hydrogel. Results from this study indicate that EDC/NHS $(8 \mathrm{mM})$ cross-linked type II collagen/HA hydrogel was capable of supporting viability of rMSCs, and furthermore their differentiation into a chondrogenic lineage. Further investigations should be conducted to determine its potential as scaffold for nucleus pulposus regeneration/repair.
\end{abstract}

Keywords: Hydrogels, hyaluronic acid, type II collagen, nucleus pulposus, mesenchymal stem cells

*Address for correspondence:

Abhay Pandit

Network of Excellence in Functional Biomaterials

National University of Ireland, Galway, Ireland

Telephone Number: 35391492758

FAX Number: 35391495585

E-mail: abhay.pandit@nuigalway.ie

\section{Abbreviations}

\section{AF: Annulus Fibrosus}

DDD: Disc degeneration diseases

DMEM: Dulbecco's Modified Eagles Medium

DSC: Differential scanning calorimetry

ECM: Extracellular matrix

EDC: 1-ethyl-3(3-dimethyl aminopropyl) carbodiime

ELISA: Enzyme-linked immunosorbent assay

FTIR: Fourier transform infrared spectroscopy

GTA: Glutaraldehyde

HA: Hyaluronic acid / Hyaluronan

IVD: Intervertebral disc

NHS: N-hydroxysuccinimide

NP: Nucleus pulposus

PBS: Phosphate buffered saline

rMSC: rat mesenchymal stem cells

TCP: Tissue culture plastic

\section{Introduction}

Neck and low back pain are the two most common causes of job-related disability with significant associated social and economic costs accounting for total annual direct healthcare costs estimated at between $\$ 50$ to $\$ 90$ billion each year in the USA (Fritz et al., 2008). Low-back pain specifically affects $1,000,000$ workers annually and is responsible for more lost workdays than any other musculoskeletal injuries (Frymoyer and Cats-Baril, 1991). These pathologies are strongly associated with degeneration of the intervertebral disc (IVD) (Urban and Roberts, 2003). Disc degeneration disease (DDD) is defined as "an aberrant cell mediated response to progressive failure" (Adams and Roughley, 2006). Most prevalent treatment modalities associated with DDD involve conservative methods including physiotherapy, drugs, and surgical interventions such as total disc or nucleus pulposus replacement and interbody fusion (Fritz et al., 2008; Strine and Hootman, 2007). However, tissue engineering strategies offer many advantages in the treatment of these spinal problems. Many forms of biomaterials have been investigated as scaffolds (i.e. alginate (Baer et al., 2001), chitosan (Roughley et al., 2006; Wan et al., 2008), type II collagen/ aggrecan/ hyaluronan (Halloran et al., 2008), fibrin/ hyaluronan (Stern et al., 2000), PLLA-hyaluronan nanofibres (Nesti et al., 2008)) all of which serve as potential cell carriers for treatment of the NP. 
IVDs are cartilaginous-like, articulating structures that lie between the vertebral bodies. These composite structures provide flexibility and integrity to the spinal column allowing controlled movement (flexion, extension and torsion) (Roberts et al., 2006; Urban and Roberts, 2003). The discs are heterogeneous tissues composed of three main parts. In the centre of the disc is present the nucleus pulposus (NP) a highly hydrated gel-like structure surrounded by a thick outer ring of fibrous tissue, the annulus fibrosus (AF). The last part, the cartilage end-plate, is a thin layer of hyaline cartilage at the interface of the disc and both vertebrae. Type II collagen is one of the main extracellular matrix (ECM) components of NP tissue. This structural protein forms a random fibril mesh-like framework that immobilises proteoglycans (PGs) and hyaluronic acid (HA) within the tissue (Cassinelli et al., 2001; Eyre et al., 2002; Humzah and Soames, 1988; Roberts et al., 1991). Maintenance of tissue hydration through the osmotic pressure is provided by the high local concentration of negatively charged PGs (i.e. chondroitin and keratan sulphate chains) (O'Halloran and Pandit, 2007; Urban and Roberts, 2003). In combination with HA and core proteins, aggrecan forms large, water-imbibing aggregates which are crucial for the biomechanical functionality of the disc (Hunter et al., 2003).

HA is a mucopolysaccharide found in various types of tissues. Its immunoneutrality makes it a biomaterial of choice for tissue engineering and drug delivery applications (Richardson et al., 2006). However, polymers based on only HA are susceptible to relatively fast degradation times by hyaluronidase in vivo (Maleki et al., 2007; Rooney and Kumar, 1993). In an effort to improve degradation resistance properties, HA was linked to type II collagen fibrils in order to form a suitable hydrogel for NP regeneration. However, the relatively poor mechanical strength and weak resistance to degradation of the noncross-linked collagen molecules themselves (O'Halloran et al., 2006) have led to the need for further stabilisation of these hydrogels.

Carbodiimides are members of a family known as "zero length" protein cross-linking reagents which promote the formation of covalent cross-links between reactive sidegroups of amino acids without actually being incorporated within the cross-link (Gratzer and Lee, 2001). An example of carbodiimide is 1-ethyl-3(3-dimethyl aminopropyl) carbodiimide (EDC). EDC stimulates carboxylic acid groups of glutamic or aspartic acid residues to react with amine groups of other chain producing amide bonds (Taguchi et al., 2002). In contrast to conventional chemical agents such as glutaraldehyde, carbodiimides have not been shown to cause any cytotoxicity because of the nonincorporation of this agent within the amide bonds (Cao and $\mathrm{Xu}, 2008$ ). The addition of $\mathrm{N}$ - hydroxysuccinimide (NHS) during the EDC cross-linking reaction has been shown to increase yields and decrease side reactions (Nakajima and Ikada, 1995).

In this study, our approach was based on the use of type II collagen and hyaluronan ( $9: 1 \mathrm{w} / \mathrm{w}$ respectively) in order to produce a hydrogel which mimicked the ratio of these constituents observed in native NP tissue (Halloran et al., 2008). In order to stabilise the composite collagen/
HA hydrogel, the carbodiimide agent, EDC associated with NHS was used. The overall goal of this work was to develop a hydrogel which could function as a carrier for MSC delivery into the NP, as a potential therapy for degenerated IVDs. The specific first aim of this study was, to optimise the concentration of EDC/NHS required to produce a stable type II collagen/HA hydrogel. The second aim was to investigate the viability, proliferation and distribution of MSCs seeded within these hydrogels.

\section{Materials and Methods}

\section{Materials}

All materials and reagents used in this study were purchased from Sigma Aldrich Ltd. (Dublin, Ireland) unless otherwise stated.

\section{Fabrication and cross-linking of type II collagen-HA hydrogels}

Type II collagen was extracted from bovine foetal calf legs obtained from Tyson Foods, IBP Fresh Meats division (Memphis, TN, USA), using pepsin treatment and salt precipitation, as previously described (Barnes et al., 2007). The collagen solution was lyophilized at $-40^{\circ} \mathrm{C}$ and kept at $-20^{\circ} \mathrm{C}$ for application.

Type II collagen was dissolved in $0.05 \mathrm{M}$ acetic acid at a final concentration of $5 \mathrm{mg} / \mathrm{ml}$, and stored at $4^{\circ} \mathrm{C}$ with gentle rocking. HA from umbilical cord (high molecular weight; 200-750kDa) was dissolved in 1X Dulbecco's Modified Eagles Medium (DMEM) complemented by $0.4 \mathrm{M} \mathrm{NaCl}$ at $1.57 \mathrm{mg} / \mathrm{ml}$. Type II collagen/HA hydrogel was used following the weight ratio 9:1. The $\mathrm{pH}$ of the mixture solution was adjusted to $\mathrm{pH} 7.4$ by the addition of $1 \mathrm{M} \mathrm{NaOH}$ aqueous solution and phosphate-buffered saline $5 \mathrm{X}$ (PBS). The viscous solutions were incubated at $37^{\circ} \mathrm{C}$ overnight to allow the natural gelation of the structure. Different ratios of EDC/NHS $(8,24,48 \mathrm{mM})$ were used for cross-linking. After addition of the cross-linker, hydrogels were incubated overnight at $37^{\circ} \mathrm{C}$. The crosslinked hydrogels were washed twice, 24 hours each, with $0.4 \mathrm{M}$ sodium chloride at $4^{\circ} \mathrm{C}$ in order to remove the residual EDC (Taguchi et al., 2002).

\section{Infrared spectroscopy}

Fourier-transformed infrared (FTIR) spectroscopy was used to confirm ester bond formation between hyaluronic acid and type II collagen of non-cross-linked and EDC/ NHS cross-linked hydrogels. Spectra were obtained with a Shimadzu FTIR-8600 (Shimadzu, Kyoto, Japan).

\section{Differential scanning calorimetry (DSC)}

Shrinking temperature of the samples was determined using a DSC instrument (DSC-60, Shimadzu). Samples of 5-8 mg were immersed in PBS (1X) for 5 hours at $4^{\circ} \mathrm{C}$. The wet samples were wiped with filter paper to remove excess PBS and hermetically sealed in aluminium pans. Hermetic pans containing air were used as reference. Heating from 25 to $100^{\circ} \mathrm{C}$ at a constant rate of $5^{\circ} \mathrm{C} / \mathrm{min}$ in air atmosphere was applied and the endothermic peak of each thermogram was monitored. 


\section{Swelling test}

Non-cross-linked hydrogels and hydrogels cross-linked by different ratios EDC/NHS (8, 24 and 48mM) were immersed in $0.4 \mathrm{M} \mathrm{NaCl}$ aqueous solution at $4^{\circ} \mathrm{C}$ for 1 hour (Gratzer and Lee, 2001). After removal of the $\mathrm{NaCl}$ solution, the hydrogels were held over a filter paper until no further dripping water was observed and then weighed. The swelling ratios of the resulting scaffolds were determined using equation (1):

$$
\text { Water uptake }(\%)=\left[\left(\mathrm{W}_{\mathrm{o}}-\mathrm{W}_{\mathrm{d}}\right) / \mathrm{W}_{\mathrm{d}}\right] \times 100
$$

where $\mathrm{W}_{\mathrm{o}}$ and $\mathrm{W}_{\mathrm{d}}$ refer to the weight of swollen and dried hydrogels respectively (Taguchi et al., 2002).

\section{HA release}

The level of HA released from the cross-linked hydrogels into the eluent after washing was measured (wash 1 and wash 2) just after gel formation using an Enzyme-linked Immunosorbent Assay (ELISA). The antigen (HA) was incubated overnight at $4^{\circ} \mathrm{C}$ in an Immuno 96 Microwell $^{\mathrm{TM}}$ plate (Nunc, Rochester, NY, USA). After 3 washes with PBS (1X) $0.05 \%$ Tween 20, the plate was incubated with a solution of PBS (1X) containing 5\% of milk overnight at $4^{\circ} \mathrm{C}$. After three washes, samples were incubated overnight at $4^{\circ} \mathrm{C}$ with the primary antibody for hyaluronic acid (Abcam, Cambridge, UK) diluted by a factor of 1,000 . After three washes, secondary antibody diluted by a factor of 1,200 coupled with biotin was incubated for 1 hour at room temperature. After three washes, a solution of streptavidin (R\&D Systems, Minneapolis, MN, USA) diluted by a factor of 200 was added. After 20 minutes of incubation at room temperature, the reaction solution was applied and incubated for 20 minutes in contact with the antibodies. After addition of the stop solution, the absorbance was read at $450 \mathrm{~nm}$ and $550 \mathrm{~nm}$. The concentration of HA released was determined by comparing the fluorescent readings of the samples to a HA concentration standard curve.

\section{Degradation by collagenase}

The hydrogels were incubated for 1 hour in $0.1 \mathrm{M}$ Tris$\mathrm{HCl}$ ( $\mathrm{pH} 7.4$ ), containing $50 \mathrm{mM} \mathrm{CaCl}_{2}$ at $37^{\circ} \mathrm{C}$. Subsequently, bacterial collagenase (extracted from Clostridium histolyticum) reconstituted in $0.1 \mathrm{M}$ Tris- $\mathrm{HCl}$ at a concentration of $10 \mathrm{U}$ was added. After incubation for 48 hours at $37^{\circ} \mathrm{C}$, the enzymatic reaction was stopped by the addition of EDTA $(0.25 \mathrm{M})$. After centrifugation $(4,000$ $\mathrm{rpm}, 5 \mathrm{~min}, 4^{\circ} \mathrm{C}$ ), precipitates were washed 3 times with distilled water and lyophilized. Mass loss was calculated by comparing the initial mass $\mathrm{W}_{\mathrm{o}}$ with the mass measured at a given time point $\mathrm{W}_{\mathrm{t}}$, as shown in equation (2):

$$
\text { Mass loss }(\%)=\left(\mathrm{W}_{\mathrm{o}}-\mathrm{W}_{\mathrm{t}}\right) / \mathrm{W}_{\mathrm{o}} \times 100
$$

\section{Mechanical testing}

Confined compression characterisation of the hydrogels was carried out using a confined compression apparatus designed to be compatible with the fittings of the Dynamic Mechanical Thermal Analyser ${ }^{\text {TM }} 2980$ instrument (DMTA тм 2980; TA Instruments, AGB Scientific Ltd, Dublin, Ireland). Briefly, the apparatus was comprised a $10 \mathrm{~mm}$ diameter confining chamber made from polytetrafluorethylene (PTFE; Dawn Lough Ltd. Galway, Ireland), with a rigid porous polyethylene (Bel-Art Products, NJ, USA) base plate (pore size ranging between 20-90 $\mu \mathrm{m}$ ). The upper plate (PTFE) was attached to the DMTA $^{\mathrm{TM}} 2980$, which was used to apply the loading forces.

Samples of $12 \mathrm{~mm}$ thickness and $5 \mathrm{~mm}$ diameter were used for measurement. A tare load of $0.025 \mathrm{~N}$ was used and the samples were loaded at a constant force rate of $0.5 \mathrm{~N} /$ minute up to a maximum $18 \mathrm{~N}$ at room temperature. For each run, the stress and strain were calculated and a graph of the same was plotted. Values of the modulus of elasticity $(E)$ were calculated as a ratio of the stress and strain in the linear region of the curves ( Perie et al., 2005; Cloyd et al., 2007; O'Halloran and Pandit, 2007;).

\section{Evaluation of the porosity of hydrogels by scanning electron microscopy}

The morphology of non-cross-linked and cross-linked hydrogels in the dry condition were observed under a Hitachi Scanning Electron Microscope (S-4700, HitachiHisco Europe GmbH, Berkshire, UK). All samples were mounted on carbon pads attached to aluminium stubs and gold coated (Emitech K550 Sputter Coater, Emitech Limited, Ashford, Kent, UK.). The porosity of the constructs was calculated after freeze-drying them at $-20^{\circ} \mathrm{C}$ in order to remove all liquid content inside the hydrogels. The porosity was evaluated using the area analysis of the area of the pore zone and the matrix zone (Garcia et al., 2007). A manual mode of the image analyser program (Image-Pro, Media Cybernetics, Bethesda, MD, USA) was used to measure the zones with arbitrary shapes.

\section{Characterisation of cell-seeded hydrogel}

Cell source and seeding. For this study, MSCs were isolated as reported previously by Neuhuber et al. (Neuhuber et al., 2004). Briefly, bone marrow was flushed from femurs and tibiae from 8-12-week-old female F-344 rats with MSC growth medium (44.5\% $\alpha$-minimal essential medium/44.5\% Ham's F-12 medium (Gibco, Invitrogen; Dun Laoghaire, Ireland)) containing $10 \%$ foetal bovine serum and $1 \%$ antibiotic/antimycotic solution (Gibco). The bone marrow cells were resuspended, centrifuged, plated, and grown in MSC growth medium. The mesenchymal cell population was isolated on the basis of their adherence to plastic, and the non-adherent hematopoietic cells were removed by regular changes in media. When cells became confluent, the cells were detached with $0.25 \%$ trypsinEDTA and then seeded at 5,500 cells per $\mathrm{cm}^{2}$, passaged they reached $90 \%$ confluence. Expression of MSC cell surface markers (CD3, CD19, CD34, CD45, CD106, CD29, CD73, CD90, and CD105) was characterized by flow cytometry. The cells were routinely grown in $\alpha \mathrm{MEM} /$ F12-Ham medium supplemented with $10 \%$ foetal bovine serum (FBS) and 1\% Penicillin/Streptomycin (P/S). The medium was changed every 2-3 days. Cells were subcultured weekly using trypsin/EDTA and maintained at $37^{\circ} \mathrm{C}$ in a humidified atmosphere of $5 \% \mathrm{CO}_{2}$. After 6 
passages, the cells were split and 50,000 cells were injected into the hydrogels at different sites. Cells were cultured for seven days at $37^{\circ} \mathrm{C}$ in a humidified atmosphere of $5 \%$ $\mathrm{CO}_{2}$. The medium was changed every 2-3 days.

Cell viability. Cell viability was measured using the AlamarBlue ${ }^{\mathrm{TM}}$ (BioSource ${ }^{\circledR}$ International, Invitrogen, Dun Laoghaire, Ireland) cell metabolic assay. This assay was performed at the following time-points, day 1 and day 7 . Monolayer culture (TCP) and non-washed hydrogels were used as positive and negative controls, respectively. Hydrogels and tissue culture plastic were washed with Hank's Balanced Salt Solution (HBSS) for 15 minutes. AlamarBlue $^{\mathrm{TM}}$ diluted by a factor of 10 in HBSS was added to each well. The cell metabolic study (AlamarBlue ${ }^{\mathrm{TM}}$ ) assay was performed using manufacturer's instructions. This assay has been shown to be effective in different cells types included stem cells (Ovcharenko et al., 2005). After 1.5 hours of incubation, the absorbance of each sample was measured in a 96-well plate at wavelengths of 550 and 595nm using a microplate reader (VICTOR3 VTM Multilabel Counter, PerkinElmer BioSignal Inc, Montreal, Canada). The percentage of AlamarBlue ${ }^{\mathrm{TM}}$ reduction was calculated using a correction factor $\mathrm{R}_{\mathrm{O}}$ as indicated by the supplier. Briefly, Ro the correction factor was calculated by dividing the absorbance of the oxidized form at lower wavelength $\left(\mathrm{AO}_{\mathrm{LW}}\right)$ by the oxidized form at higher wavelength $\left(\mathrm{AO}_{\mathrm{RW}}\right) \cdot\left(\mathrm{R}_{\mathrm{O}}=\mathrm{AO}_{\mathrm{LW}} / \mathrm{AO}_{\mathrm{HW}}\right)$. The percentage of reduction was then calculated according to equation (3):

$$
A R_{L W}=A_{L W}-\left(A_{H W} \times R_{O}\right) \times 100
$$

\section{Cell proliferation}

Hydrogels were digested overnight at $56^{\circ} \mathrm{C}$ by $0.5 \mathrm{mg} / \mathrm{mL}$ of proteinase K. PicoGreen ${ }^{\circledR}$ Assay (Invitrogen, Dun Laoghaire, Ireland) was used in accordance with the instructions provided by the supplier. The DNA content of the samples was quantified by interpolating values from a linear standard curve.

\section{Cell distribution}

Cell distribution inside the hydrogels was determined by confocal laser scanning microscopy. The samples were fixed with a solution of $4 \%$ paraformaldehyde $/ 2 \%$ sucrose overnight at $4^{\circ} \mathrm{C}$, then incubated in a permeabilising solution consisting of $0.2 \%$ Triton-X for one hour. The samples were stained with rhodamine-phalloidin (Invitrogen) for 20 minutes to obtain structural staining (microfilament staining), then with ToPro3 (Invitrogen) for 10 minutes to obtain nuclear staining at room temperature. Constructs were imaged using a confocal microscope with a multiphoton laser source.

\section{Evaluation of rMSCs differentiation into chondrocyte-like cells within the hydrogel}

Cross-linked $8 \mathrm{mM}$ EDC/NHS type II collagen/HA hydrogels were seeded as previously described at a concentration of 50,000 cells into the hydrogels. Two groups were cultured with (1) $\alpha \mathrm{MEM} / \mathrm{F} 12-\mathrm{Ham}$ medium supplemented with $10 \% \mathrm{FBS}$ and $1 \% \mathrm{P} / \mathrm{S}(2) \alpha \mathrm{MEM} / \mathrm{F} 12-$
Ham medium supplemented with 50nM ascorbic acid, $10 \mathrm{ng} / \mathrm{mL}$ TGF- $\beta 1$ and $6.25 \mu \mathrm{g} / \mathrm{mL}$ ITS (Insulin $(6.25 \mu \mathrm{g} /$ $\mathrm{ml})$ Transferrin $(6.25 \mu \mathrm{g} / \mathrm{ml})$ Selenite $(6.25 \mathrm{ng} / \mathrm{ml}))$. Medium was changed every 2-3 days for 21 days. Monolayer cultures and pellet cultures with the same treatment were used as control. After 21 days, total RNA was extracted using a variant of Trizol isolation. Briefly, TriReagent ${ }^{\circledR}$ (Invitrogen) was added onto the structures. Hydrogels were mechanically disrupted using a Tissue Ruptor (Qiagen, West Crawley, Sussex, UK). Phase separation was performed by adding chloroform (SigmaAldrich, Ireland), and total RNA was purified using an RNeasy kit (Qiagen), according to the supplier's recommended procedure. Total RNA quantity and purity were determined using an ultraviolet spectrometer (NanoDrop ND-1000 Spectrophotometer, NanoDrop Technologies, Wilmington, DE, USA). RNA integrity was checked electrophoretically using the RNA 6000 Nano LabChip kit on Agilent Bioanalyser 2100 (Agilent Technologies, Dublin, Ireland). Reverse transcription (RT) was performed using the ImProm-II RT system according to the manufacturer's protocol (Promega, Southampton, UK). Gene transcription was examined using real-time RTpolymerase chain reaction (PCR). Reactions were performed and monitored using an ABI 7000 sequence detection system (Applied Biosystems, Life Technologies, Carlsbad, CA, USA) using the TaqMan gene expression system (TaqMan, Applied Biosystems) and specific primer sequence for type II collagen (NM_012929.1), type I collagen (NM_053304.1), and aggrecan (NM_022190.1). Gene transcription was inferred from calibration samples and normalized in relation to transcription of the housekeeping rodent GAPDH. The $2^{-\Delta \Delta C t}$ method was used to calculate relative gene expression for each target gene.

\section{Statistical analysis}

Data shown are representative of repeated experiments. Triplicate samples were used for chemical and biochemical assays, and duplicate samples for microscopy analysis. Numerical data is expressed as mean \pm standard error of the mean. Analysis was performed using the statistical software MINITAB ${ }^{\mathrm{TM}}$ (version 15, Minitab, Inc., Coventry, UK). Quantitative data were analysed using the $t$-test. Statistical significance was set at $p<0.05$.

\section{Results}

\section{Characterisation of type II collagen/HA hydrogels}

Infrared spectroscopy. Infrared spectrometry was used to determine the chemical modification of type II collagen/ HA during cross-linking. Figure 1 shows FT-IR spectra obtained for the different types of cross-linked type II collagen/HA hydrogels. With increasing EDC/NHS concentration, the formation of amide bonds $\left(1650 \mathrm{~cm}^{-1}\right)$ and ester bonds $\left(1025 \mathrm{~cm}^{-1}\right)$, and the diminution of carboxyl and amine free groups $\left(3100-3500 \mathrm{~cm}^{-1}\right)$ were observed. Furthermore, a decrease of symmetric stretching band of carboxylate salts $\left(1450 \mathrm{~cm}^{-1}\right)$ was also observed. 


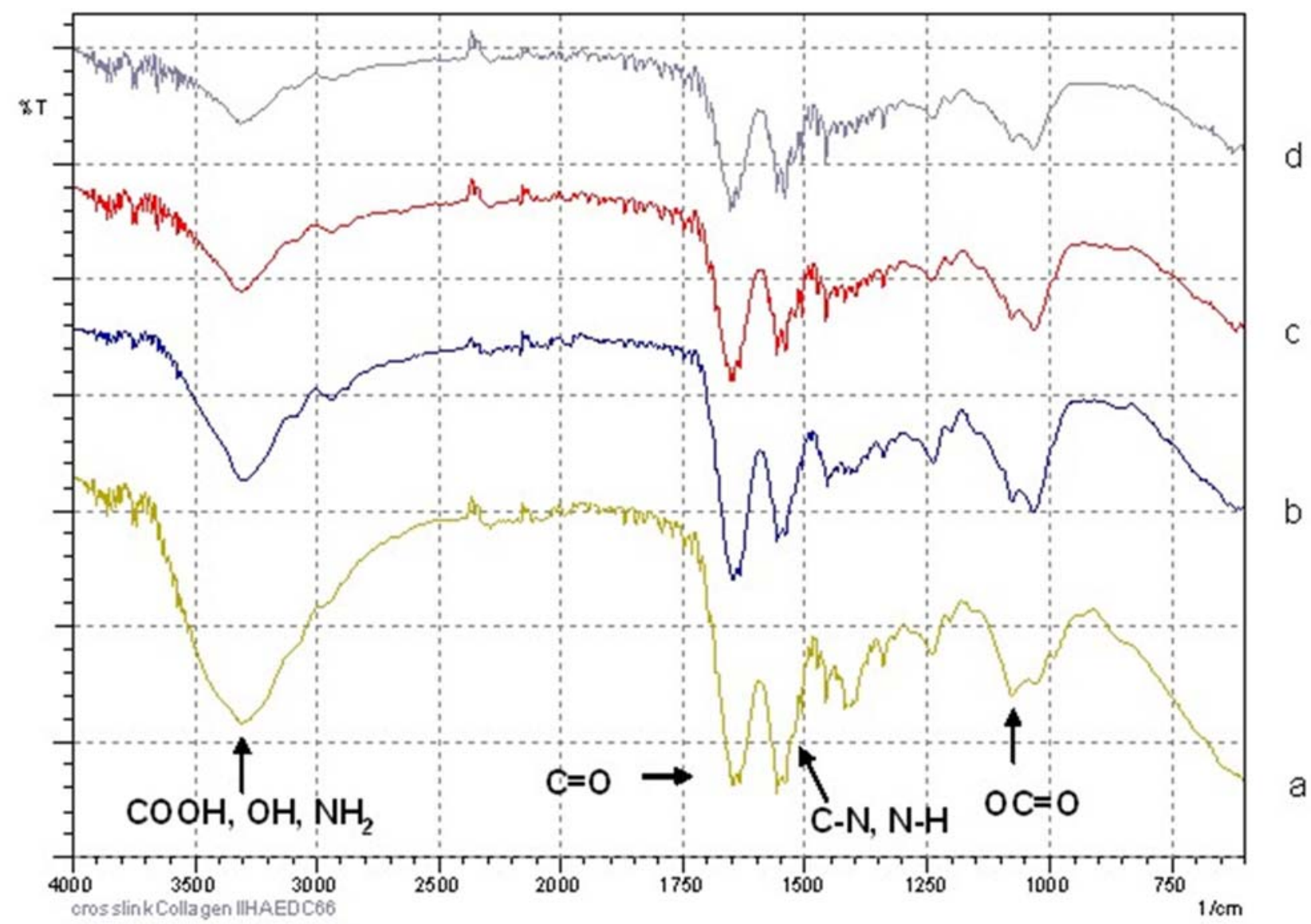

1/an

Fig. 1. FT-IR spectra of type II collagen/HA hydrogels. IR spectra of non-cross-linked a) and cross-linked with $8 \mathrm{mM} \mathrm{b}), 24 \mathrm{mM} \mathrm{c}$ ), and $48 \mathrm{mM}$ of EDC/NHS d) hydrogels.

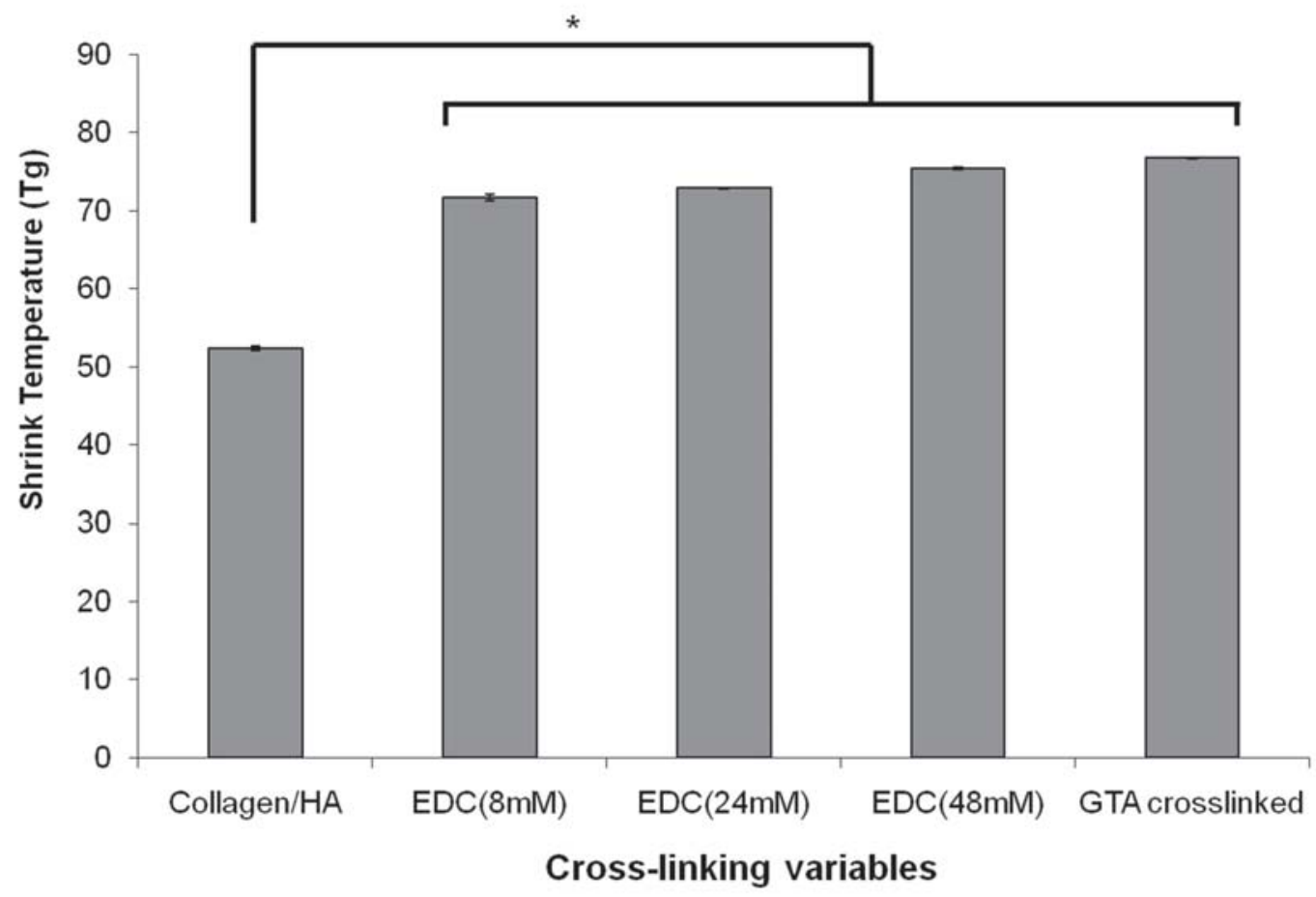

Fig. 2. Denaturation temperature $\left(\mathrm{T}_{\mathrm{g}}\right)$ of type II collagen/HA hydrogels. The $\mathrm{T}_{\mathrm{g} \text { of }}$ type II collagen/HA samples as measured by DSC before and after cross-linking. Data represent mean \pm standard error $(n=3)$. The symbol * indicates a statistical significance of $p<0,05$ for all comparisons. 


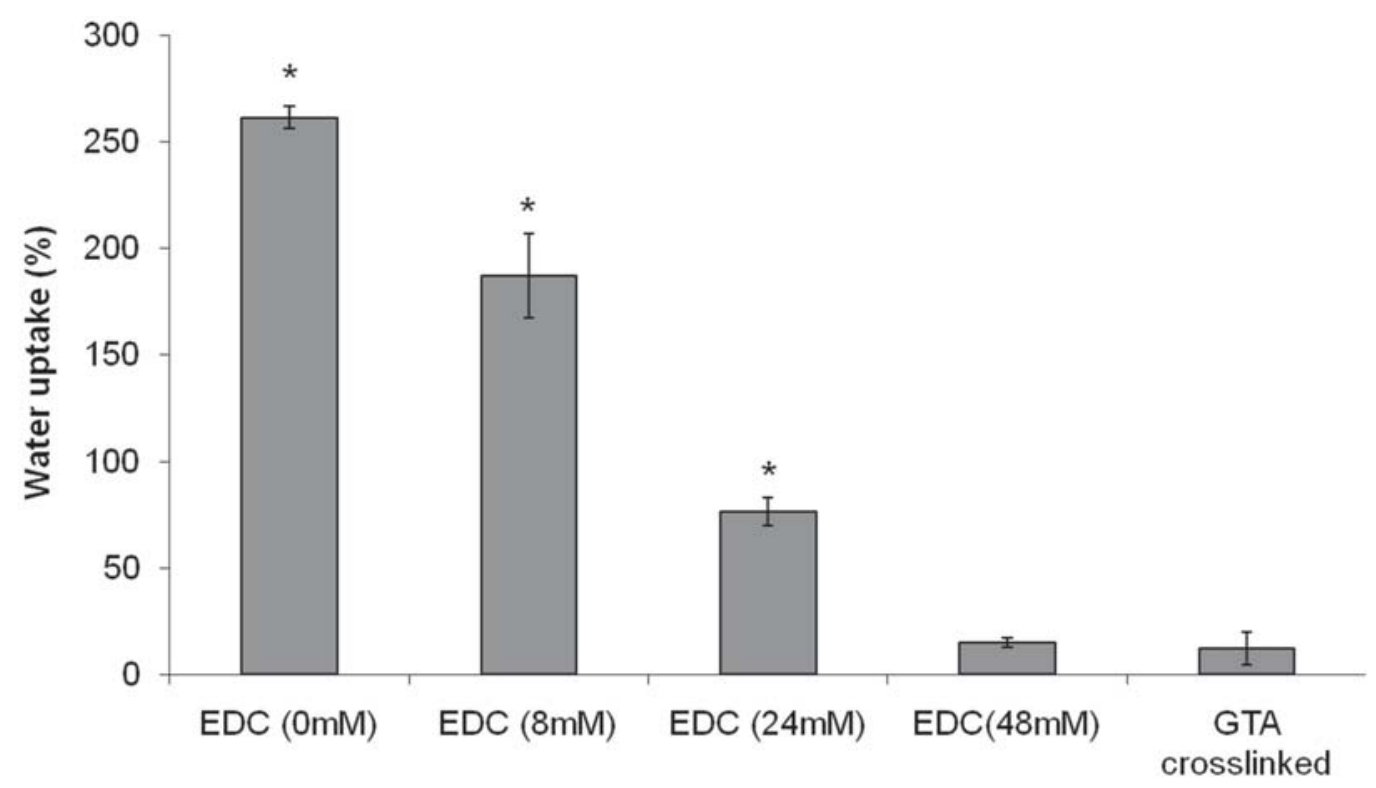

Cross-linking variables

Fig. 3. Relative water uptake of type II collagen/HA hydrogels. Hydrogels were cross-linked with different EDC/ NHS concentrations and were compared with non-cross-linked and glutaraldehyde (GTA) cross-linked hydrogels. Data represent mean \pm standard error $(n=3)$. The symbol $*$ indicates a statistical significance of $p<0.05$ for all comparisons.

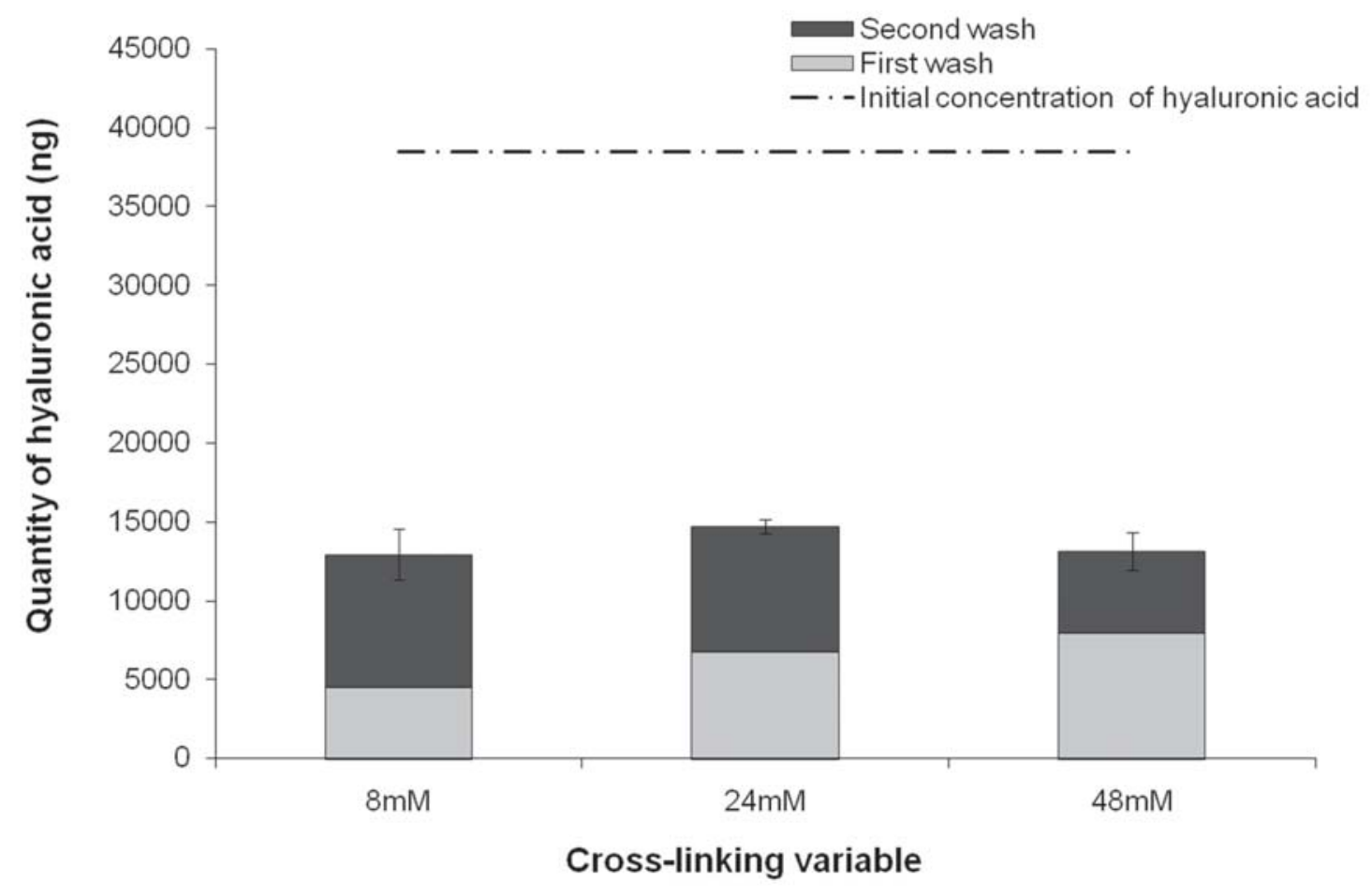

Fig. 4. HA release after repeated rinsing (Grey: First wash, Black: Second wash). No significant difference of release was observed between the three different cross-linked hydrogels ( $t$-test $0.05 \%)$. Data represent mean \pm standard error $(n=3)$ 

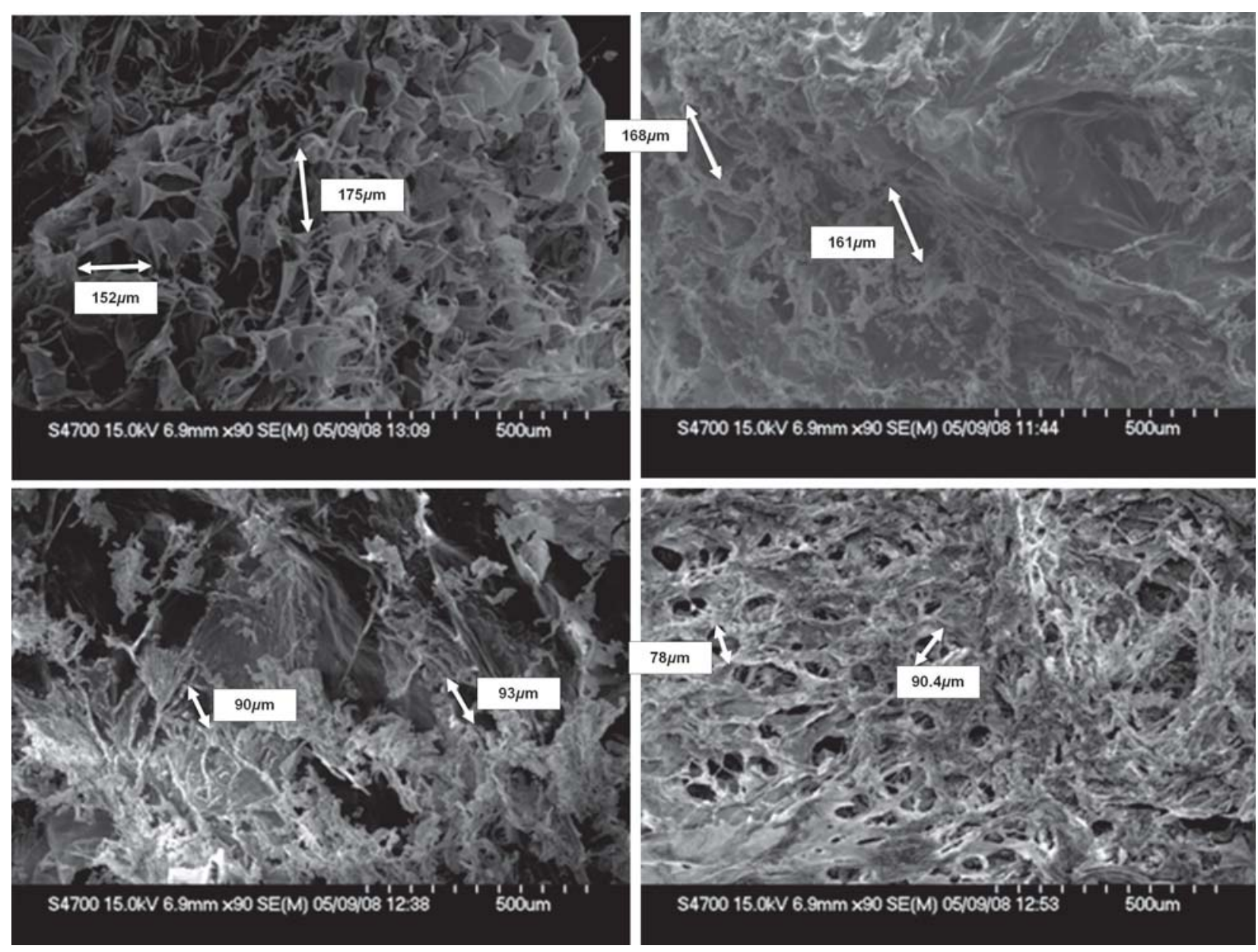

Fig. 5. Scanning electron microscope images of type II collagen/HA hydrogels. SEM images of non-cross-linked a), $8 \mathrm{mM} \mathrm{b}), 24 \mathrm{mM} \mathrm{c}$ ) and $48 \mathrm{mM} \mathrm{d}$ ) of EDC/NHS cross-link samples at x90 magnification.

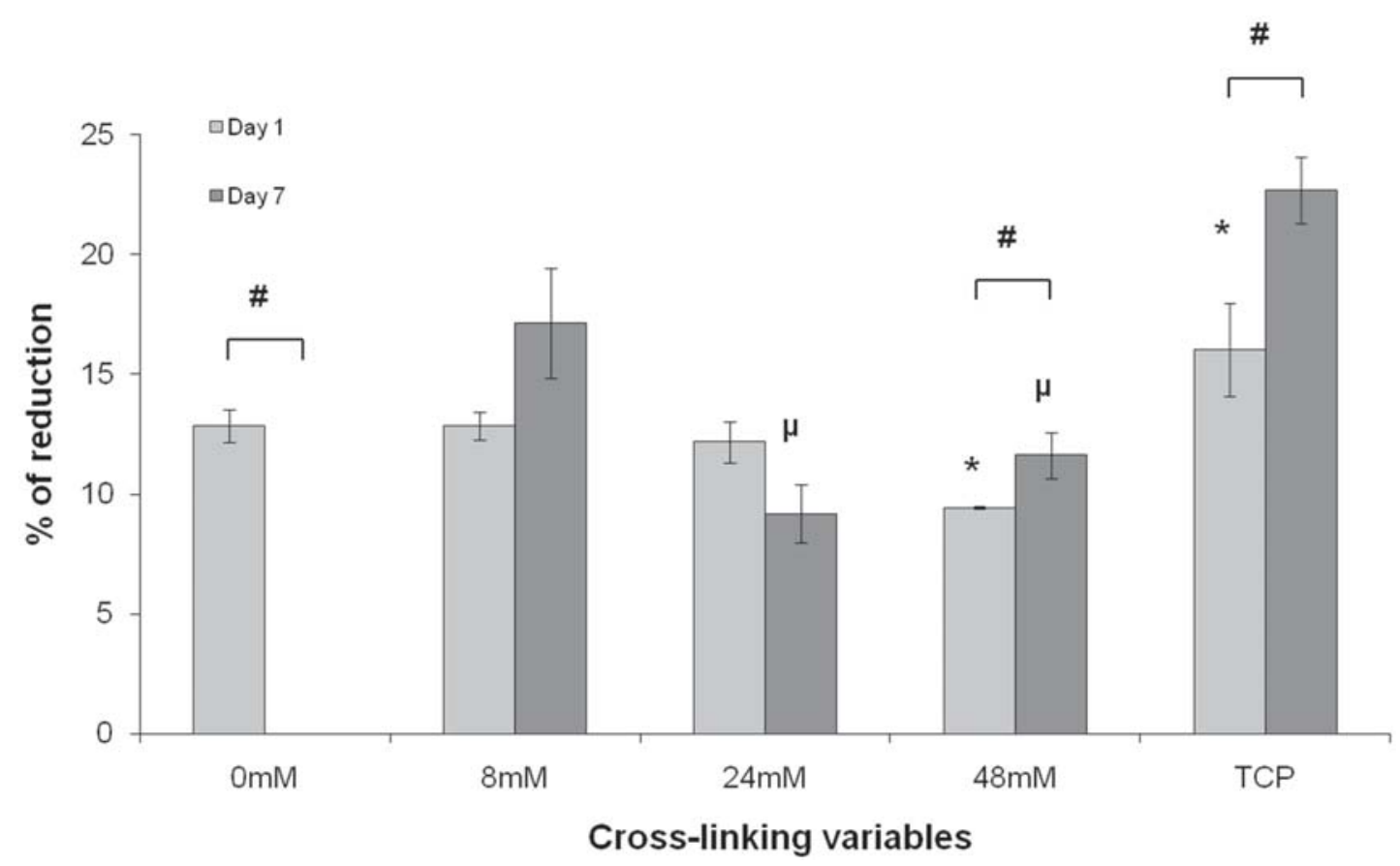

Fig. 6. AlamarBlue ${ }^{\mathrm{TM}}$ assay showing rMSC activity after seeding within different hydrogels after 1 and 7 days of culture. A non cross-linked type II collagen/HA (coll/HA) was used as a control. Data represent mean \pm standard error $(n=3)$. Significant difference is indicated with similar symbols; this represents a significant difference of activity of cells seeded in the different hydrogels $(p<0.05)$. 


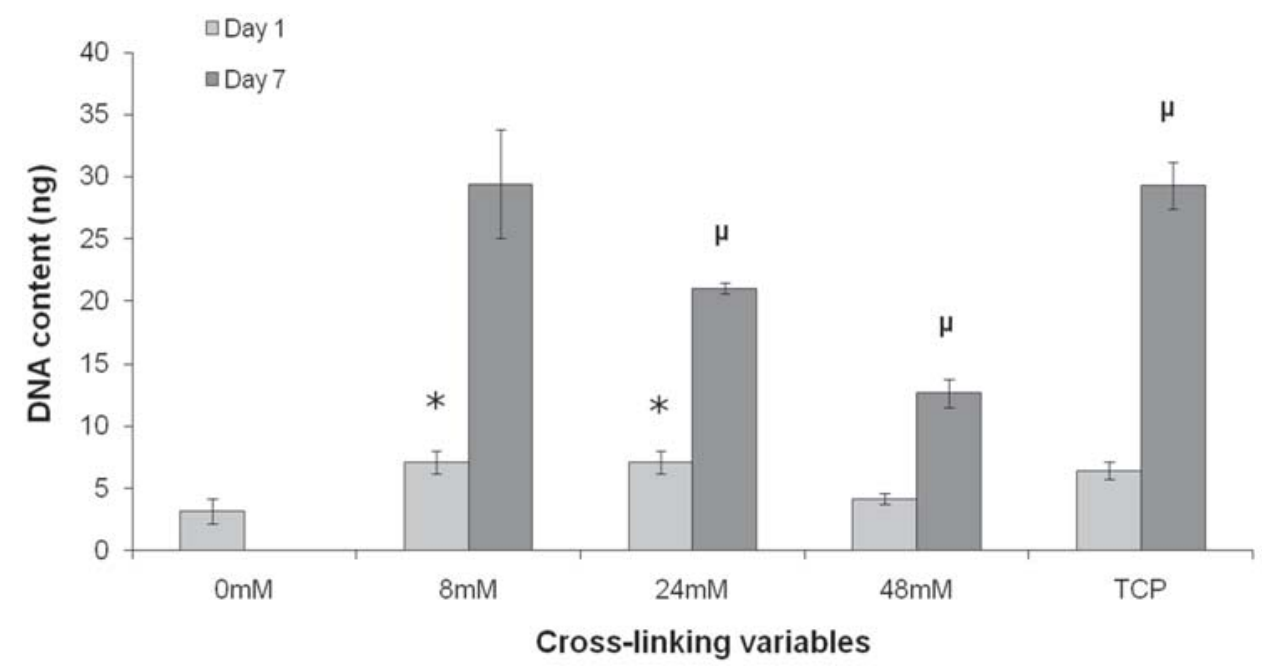

Fig. 7. DNA content present in the hydrogel after 1 and 7 days of culture. A non cross-linked type II collagen/HA and a tissue culture plastic culture were used as controls. Data represent mean \pm standard error $(n=3)$. Similar symbols denote statistical difference between the different groups ( $t$-test $0.05 \%)$.
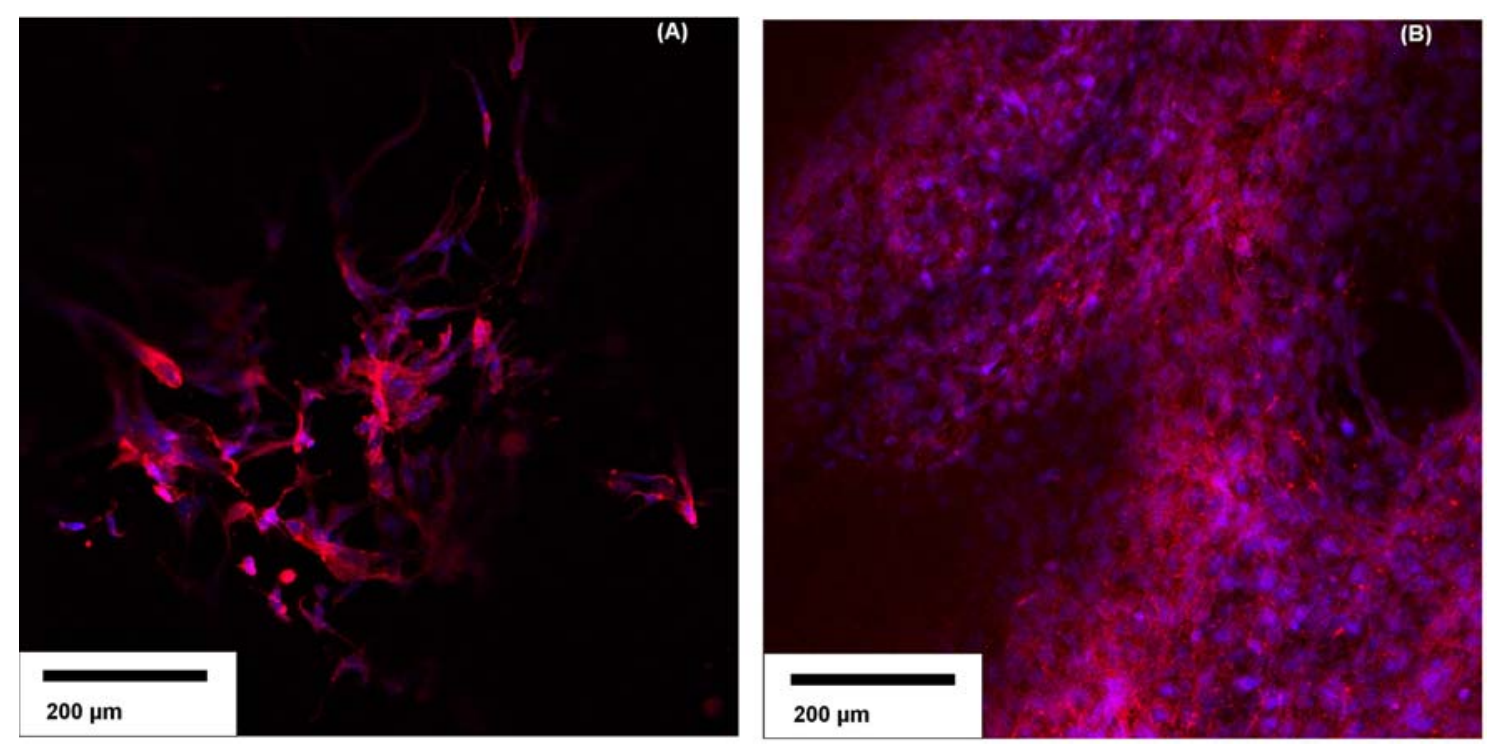

Fig. 8. rMSCs distribution after 7-day seeding within the hydrogel $8 \mathrm{mM}$ after (A) 1 day and (B) 7 days The nuclei appear in blue (Topro3 staining), the cytoskeletons appear in red (rhodamine-phalloidin staining). Scale bar: $200 \mu \mathrm{m}$.

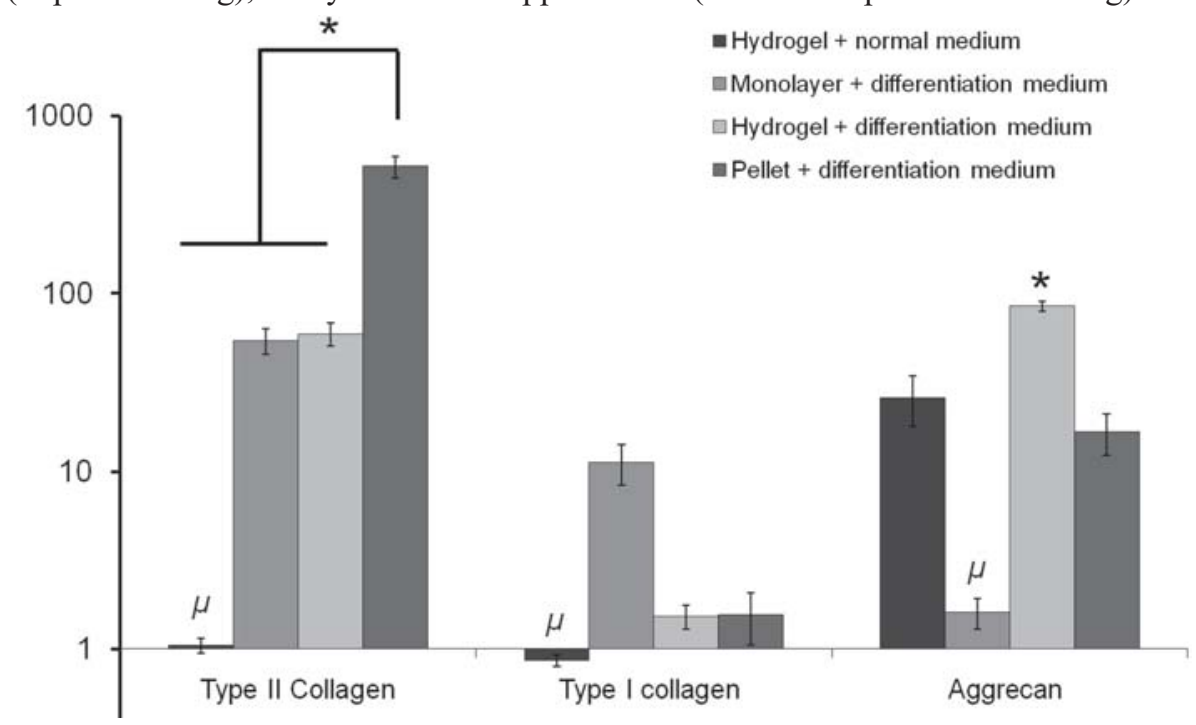

Fig. 9. Type II collagen, type I collagen and aggrecan mRNA expressions relative to monolayer culture after 21 days in culture. Hydrogels were cultured in absence and presence of differentiation medium. Monolayer with differentiation medium was used as positive control. Data represent mean \pm standard error $(n=3)$. ${ }^{*}$ and $\mu$ denote statistical difference between the marked group and the other groups; Student $t$-test, ${ }^{*} p<0.05$. 
Table 1. Mass loss of type II collagen/HA hydrogels.

\begin{tabular}{|c|c|c|c|c|c|}
\hline Samples & $\begin{array}{c}\text { EDC } \\
\mathbf{( 0 m M )}\end{array}$ & $\begin{array}{c}\text { EDC } \\
\mathbf{( 8 m M )}\end{array}$ & $\begin{array}{c}\text { EDC } \\
\mathbf{( 2 4 m M )}\end{array}$ & $\begin{array}{c}\text { EDC } \\
\mathbf{( 4 8 m M )}\end{array}$ & $\begin{array}{c}\text { GTA } \\
\text { cross-linked }\end{array}$ \\
\hline Mass loss (\%) & $34 \pm 0.0231 *$ & $1.9 \pm 0.0023$ & $1.8 \pm 0.0017$ & $1.5 \pm 0.0017$ & $1.6 \pm 0.0005$ \\
\hline
\end{tabular}

Percentages of degraded cross-linked collagen/HA scaffolds. Data represents mean \pm standard error $(n=3) *$ indicates significant difference between groups $(p<0.05)$.

Differential scanning calorimetry. The shrink temperature $\left(\mathrm{T}_{\mathrm{g}}\right)$ of type II collagen/HA hydrogels stabilised by different concentrations of EDC/NHS are presented in Figure 2. Non-cross-linked type II collagen/ HA hydrogel has a $\mathrm{T}_{\mathrm{g}}$ of $52.39 \pm 0.22^{\circ} \mathrm{C}$. The $\mathrm{T}_{\mathrm{g}}$ of EDC/ NHS-cross-linked collagen/HA hydrogels increased to $+71.76 \pm 0.43^{\circ} \mathrm{C}$ and $+75.44 \pm 0.08^{\circ} \mathrm{C}$ for concentrations of $8 \mathrm{mM}$ and $48 \mathrm{mM}$ respectively. No significant differences were seen in the shrink temperatures between the EDC/ NHS cross-linked samples. Furthermore, glutaraldehyde (GTA) cross-linking showed a comparable increase in the shrink temperature to $+76.76 \pm 0.04^{\circ} \mathrm{C}$. The results indicate that EDC/NHS cross-linked scaffolds increased the shrink temperature.

Swelling test. Swelling properties of the different types of hydrogels were evaluated by the measure of the relative water uptake (Fig. 3). Non-cross-linked hydrogel showed a relative water uptake of $261.46 \pm 3.74 \%$. Increase EDC/ NHS concentration $(8 \mathrm{mM}, 24 \mathrm{mM}, 48 \mathrm{mM})$ decreased the swelling properties respectively $(186.94 \pm 13.95 \%, 76.67$ $\pm 4.71 \% *$ and $14.48 \pm 1.68 \% *)$. ${ }^{*}$ denotes a significant difference between the different groups.

HA release. HA release from the hydrogels was quantified by ELISA. Between 30 and $40 \%$ of the initial concentration of HA was lost following these steps $(33.7 \pm 4.12 \%$ for $8 \mathrm{mM}, 38.2 \pm 1.13 \%$ for $24 \mathrm{mM}$ and $34.1 \pm 3.05 \%$ for $48 \mathrm{mM}$ ) (Fig. 4). No significant differences in the release of HA were noted between the three different cross-linked hydrogels.

Degradation by collagenase. The results are shown in Table 1 as percentages of degraded EDC/NHS cross-linked collagen/HA hydrogels relative to non-cross-linked hydrogels. Hydrogels cross-linked with EDC/NHS revealed only a partial degradation ( $2 \%$ ) after $48 \mathrm{~h}$ of collagenase treatment compared with non-cross-linked hydrogels (34\%).

Mechanical testing. Table 2 shows an increase in compressive modulus at $20 \%$ strain from $27.6 \pm 6.5$ to $171.9 \pm 27.89 \mathrm{kPa}$ which indicates that cross-linking with EDC/NHS increased the modulus approximately six times that of the non-cross-linked hydrogels. Non-cross-linked hydrogels were mechanically weaker than the cross-linked hydrogels.

Scanning electron microscopy. Non-cross-linked and cross-linked type II collagen/HA hydrogels $8,24,48 \mathrm{mM}$ of EDC/NHS show a mean pore size of $196.75 \pm 2.01$, $164.5 \pm 2.22,91.5 \pm 1.45$ and $79.1 \pm 1.24 \mu \mathrm{m}$, respectively (Fig. 5). A significant decrease was noted when the EDC concentration was increased $\left(\mathrm{R}^{2}=0.94\right)(p<0.05)$.

\section{Characterisation of cell-seeded hydrogel}

Cell viability The metabolic activity of rMSCs seeded within the hydrogels was evaluated using the AlamarBlue $^{\mathrm{TM}}$ assay. This activity is correlated with the viability of the cells present inside the hydrogel. Nonwashed EDC/NHS hydrogels were used as negative control. However, cells were dead due to the toxicity of the cross-linker and no cell activity was observed.

A significant difference of activity was observed at day 1 between the hydrogel cross-linked by of the couple EDC/ NHS and the non-cross-linked hydrogels. After 7 days in culture, complete degradation of the non-cross-linked hydrogel was due to the instability of collagen in culture medium (Sakai et al., 2006). Hence no data for this time point is reported. No significant difference was observed between the cross-linked hydrogel $8 \mathrm{mM}$ and the control (tissue culture plastic (TCP)) for this time point. However, a significant difference was seen between $8 \mathrm{mM}$ crosslinked hydrogel and the control, and the $24 \mathrm{mM}$ and $48 \mathrm{mM}$

Table 2. Compressive stress and modulus of type II collagen/HA hydrogels.

\begin{tabular}{|c|c|c|c|c|c|}
\hline Samples & $\begin{array}{c}\text { EDC } \\
\mathbf{( 0 m M )}\end{array}$ & $\begin{array}{c}\text { EDC } \\
\mathbf{( 8 m M )}\end{array}$ & $\begin{array}{c}\text { EDC } \\
\mathbf{( 2 4 m M )}\end{array}$ & $\begin{array}{c}\text { EDC } \\
\mathbf{( 4 8 m M )}\end{array}$ & $\begin{array}{c}\text { GTA } \\
\text { cross-linked }\end{array}$ \\
\hline $\begin{array}{c}\mathbf{2 0 \%} \\
\text { Strain, } \\
\mathbf{k P a}\end{array}$ & $27.6 \pm 6.5^{*}$ & $48.9 \pm 2.71^{\nabla}$ & $122.6 \pm 5.48$ & $171.9 \pm 27.89$ & $188.1 \pm 23.32$ \\
\hline $\begin{array}{c}\text { Modulus, } \\
\mathbf{k P a}\end{array}$ & $1.4 \pm 0.35^{*}$ & $2.4 \pm 0.12^{\nabla}$ & $6.2 \pm 0.29$ & $8.6 \pm 1.15$ & $10.3 \pm 0.40$ \\
\hline
\end{tabular}

Compressive stress $(\mathrm{kPa})$ and compressive modulus values of confined system at $20 \%$ strain. Data represents mean \pm standard error $(\mathrm{n}=3)$. Significant differences were observed between $0 \mathrm{mM}\left({ }^{*}\right)$ and all other groups and between $8 \mathrm{mM}$ $(\nabla)$ and all the rest of the groups $(p<0.05)$. 
cross-linked hydrogels. Cell activity was observed to increase after 7 days of culture for cross-linked hydrogels $8 \mathrm{mM}$ and $48 \mathrm{mM}$. Nevertheless, a decrease of activity was observed for the cross-linked hydrogel $24 \mathrm{mM}$ (Fig. 6).

Cell proliferation. The level of rMSC proliferation was examined after 7 days of culture for each type of hydrogels. No significant difference in DNA content was observed between the cross-linked hydrogels 8 and $24 \mathrm{mM}$ EDC/ NHS and the control (tissue culture plastic) after 1 day in culture. DNA content was lower than in the non-crosslinked hydrogel group as well as for the cross-linked hydrogel $48 \mathrm{mM}$ after 1 day and 7 days in culture. The highest cell number was observed after cross-linking with $8 \mathrm{mM}$ than with 24 and $48 \mathrm{mM}$ after 7 days (Fig. 7).

Cell distribution Cell distribution inside the hydrogel after 7 days in culture was observed by confocal microscopy. Cells proliferated, independent of the cross-linker concentration, in every plane which confirmed the homogenous distribution of cells inside the hydrogel (Fig. $8 \mathrm{~B})$. A cell confluence after 7 days was noted in the hydrogels which confirmed the observation following the proliferation study (i.e. cell proliferation between 1 and 7 days in culture (Fig. 8). However, a difference of proliferation rate was seen between the hydrogels crosslinked with 8 and $48 \mathrm{mM}$ (data not shown).

rMSCs gene expression after 21 days in culture. Immediately after seeding, differentiation medium was added. Cells were cultured in the hydrogels in presence and absence of differentiation medium. Monolayer cultures were used as control and data were normalised relative to non-treated monolayer cells. An increase of aggrecan mRNA expression was observed after culture into the hydrogel in complete medium (26.0 \pm 5.54 -fold). However, type II collagen expression was not induced by this type of culture. Type I collagen was maintained low. After induction by differentiation medium, type II collagen expression increased $59.1 \pm 8.87$-fold, as much as the induced-monolayer culture $(54.1 \pm 8.93$-fold $)$. A high expression of type II collagen was observed after culture in pellet (519.3 \pm 71.04 -fold). Type I collagen expression was maintained low after induction of differentiation into the hydrogels $(1.5 \pm 0.24$-fold $)$ and after culture in pellet $(2.2 \pm 0.51$-fold $)$ whereas after induction of differentiation in monolayer the expression increased $11.3 \pm 2.92$-fold. Aggrecan production was significantly higher in rMSCs that were cultured in three dimensions in presence and absence of differentiation medium in the hydrogel (respectively, $84.8 \pm 8.16$ and $26.1 \pm 5.54$-fold) and after culture in pellet $(16.8 \pm 4.4$-fold $)$ compared to monolayer culture in the presence of differentiation medium (1.6 \pm 0.31-fold).

\section{Discussion}

The intervertebral disc degeneration is one of the prevalent causes of neck and low back pain. Currently, disc degeneration diseases require partial or complete discectomy. The use of biomaterials helps to restore the disc volume after discectomy and prevent loss of disc weight. The association biomaterials-stem cells is one of the most promising approaches in the disc therapy (Richardson et al., 2006; Risbud et al., 2004; Sobajima et al., 2007). The importance of a biomaterial as carrier of stem cells has previously been shown (Sakai et al., 2006). For these reasons, we have developed in this study a type II collagen/HA hydrogel as carrier of bone marrow mesenchymal stem cells for intervertebral disc regeneration.

The type II collagen molecule has natural properties of gelation at $37^{\circ} \mathrm{C}$. However, after 7 days in culture, complete degradation of the non-cross-linked hydrogel due to the instability of collagen in culture medium is noticed (Sakai et al., 2006). In order to enhance the stability of the composite hydrogel developed in this study, the chemical agent EDC associated with NHS was used. EDC is known to activate carboxyl groups in aqueous or organic solutions. The activated carboxyl groups are then able to react with hydroxyl or primary amines resulting in ester or amide bonds (Barnes et al., 2007). The shrinking temperature $\left(\mathrm{T}_{\mathrm{g}}\right)$ is a measure of the thermal energy required to break the intra-molecular hydrogen bonds that stabilise the collagen triple helix. When this helix is further stabilised by exogenous cross-links, $T_{s}$ can be used as an indirect measure of cross-linking (Nakajima and Ikada, 1995). During this study, an increase of the $\mathrm{T}_{\mathrm{g}}$ was observed when the concentration of EDC/NHS increases (Fig. 1). Noncross-linked hydrogel has a low $\mathrm{T}_{\mathrm{g}}$ due to the absence of native collagen fibrils (Pieper et al., 2002).

In order to characterise the degree of cross-linkage of the different type II collagen/HA hydrogels, swelling ratios were measured. It was determined that one hour was sufficient for these highly porous hydrogels to reach equilibrium. The best swelling ratio is reported to be obtained in $0.4 \mathrm{M} \mathrm{NaCl}$ aqueous solution at $4^{\circ} \mathrm{C}$ due to the electrostatic interaction induced by sodium and chloride ions (Taguchi et al., 2002). Glutaraldehyde and EDC/NHS cross-linked hydrogels had a much lower water uptake indicating a higher degree of cross-linking in these samples (Figure 3). The high swelling property of these hydrogels seems to be dependent on the porous structure which has an absorbent characteristic (Patel and Amiji, 1996). With increasing EDC/NHS concentration, a significant decrease in the swelling ratio was detected.

The EDC molecule is toxic for cells at specific doses (Saito et al., 2008). Based on the optimal swelling properties of the hydrogels, EDC molecules were eliminated. However, a loss of HA due to the swelling properties of the substitute in non-cross-linked and crosslinked scaffolds during washes and tissue culture applications has been reported (Tang et al., 2006). Ultimately, the addition of HA into this hydrogel is intended to improve structural support and enhanced cell differentiation and proliferation (Nesti et al., 2008). It consequently was essential to quantify the amount of HA release throughout these steps. The wash steps were performed in the optimal swelling conditions in order to remove all the molecules of EDC/NHS (Gratzer and Lee, 2001). In culture, these optimal conditions were not 
followed (hydrogels were incubated at $37^{\circ} \mathrm{C}$ without a supplementation of $0.4 \mathrm{M} \mathrm{NaCl}$ ). Therefore, the swelling properties can be expected to be relatively minimal as the release of HA. However, a rate of release of HA can be predicted due to the cell activities and the natural osmotic pressure in the media. Nevertheless, as the IVD is in confinement conditions in vivo; the HA released will be entrapped into the system or the disc. After washing, HA still represents $7 \%$ of the hydrogel final composition. This final concentration is sufficient to have a significant impact on the behaviour of cells that are seeded within the hydrogel. The HA concentration was determined according to previous studies which have used various concentrations of HA ranging from 0.01 to $6 \mathrm{mg} / \mathrm{mL}$ (Kawasaki et al., 1999; Tang and Spector, 2007; Tang et al., 2006). The aggregating capacity of isolated proteoglycans in vitro was determined by incubating proteoglycans with $2 \%$ hyaluronan. Furthermore, it was stated that combining $2 \%$ hyaluronan to aggrecan (w/w) resulted in significant macromolecular formation( Zhu et al., 1996; O'Halloran and Pandit, 2007). The final concentration of HA present in the hydrogel would be sufficient to allow the formation of aggregates after interaction with aggrecans. Proteoglycans from intervertebral disc as in cartilage bind specifically to hyaluronate to form high-molecular-weight aggregates via a globular domain at the $\mathrm{N}$-terminus of the proteoglycan protein core (Bonnet et al., 1985; Tengblad et al., 1984). Both contain other 'link-protein' molecules in addition to proteoglycan and hyaluronate. This molecule binds stoichiometrically to each proteoglycan and interacts with hyaluranonate. The link-proteins are an integral part of the aggregate structure forming additional bonds possibly by bridging the proteoglycan molecule and the hyaluronate chain (Bonnet et al., 1985; Hardingham, 1979). Furthermore, this final concentration is sufficient to have a significant impact on the behaviour of cells that are seeded within the hydrogel (Andhare et al., 2009). The release of HA and other extracellular molecules is expected to be minimal (Chiba et al., 1998; O'Halloran and Pandit, 2007). Aggrecan produced by the cells will likely bind to HA to create aggregates ( O'Halloran and Pandit, 2007; Colombini et al., 2008;). These aggregates will allow for the retention of water within the disc and the restoration of the disc function. Their presence would be evaluated by detection the link-proteins by immunochemistry.

However, additional studies are required to compare the cellular response to this release and presence of HA.

The rationale for using a hydrogel-based scaffold for disc regeneration is to restore the biomechanical properties of the NP to that of native, non-degenerated NP to support normal disc function (Cloyd et al., 2007). These biomechanical properties are attributed to the structure of the non-degenerated NP extracellular matrix, i.e. high aggrecan content. The aggrecan macromolecule's constituents (chondroitin and keratan sulphate chains attached to core proteins) ensure the maintenance of tissue hydration through osmotic pressure ( Urban and Roberts, 2003; O'Halloran and Pandit, 2007). Associated with HA, aggrecan forms large aggregates which allow the high level of water retention (Colombini et al., 2008; Horner et al.,
2002). This characteristic makes the disc a highly hydrated structure (Urban and Roberts, 2003). The potential for a hydrogel as an NP scaffold is based on its ability to swell (Cloyd et al., 2007). Furthermore, the retention of glycosaminoglycans (GAGs) in the hydrogels is an important function that previous studies on NP tissue engineering replacements using cell-seeded scaffolds have reported (Alini et al., 2003; Halloran et al., 2008; Stern et al., 2000). Thus, it was hypothesised that incorporation of HA in the hydrogel under investigation might allow in vivo the formation of these aggregates and, consequently, the retention of water inside the disc.

The degradation of the collagen/HA hydrogels has previously been studied by exposure of the hydrogel to a collagenase solution in order to determine the level of cross-linking of the hydrogels and their stability in order to inhibit enzymatic degradation (Pieper et al., 2002). Bacterial collagenase has been shown to be more active than eucaryotic degradation (Lecroisey and Keil, 1979) and this enzyme cleaves the three chains of native triple helical type I, II and III collagens after Gly in a particular sequence (Gln/Leu)-Gly\#(Ile/Leu)-(Ala/Leu) (\# indicates the bond cleaved) located approximately three quarters away from the $\mathrm{N}$-terminus of the collagen molecules (Chung et al., 2007). Data obtained from in vitro collagenase experiments demonstrate the increased resistance of cross-linked samples to enzymatic degradation (Table 1). The resistance to degradation may also be due to the retention of the cleaved peptide fragments by the newly formed cross-links (Charulatha and Rajaram, 2003) and the higher cross-linked density that impedes the accessibility of collagenase enzyme molecules within the hydrophilic chemical groups.

These hydrogel degradation results, in combination with the findings observed with infrared spectroscopy and DSC, suggest that EDC/NHS cross-linking improved the stability of the hydrogels. However, the increased level of stability attained was found to be independent of the concentrations of EDC/NHS used.

The challenge for any scaffold used as an NP replacement is to adequately mimic the properties and functionality of the native NP. The task of finding a mechanically comparable replacement scaffold is difficult and must focus on characteristics critical to NP function as it relates to motion segment mechanics (Cloyd et al., 2007). The confined compression mode was used to examine the stress-strain behaviour of each sample. Although not semi-confined, as is the case in vivo, this mode of mechanical testing was shown to produce the most repeatable results and to be the closest replicate to the in vivo environment (Perie et al., 2005). The variation in the hydrogels' dimensions under compression loading can be attributed to a combination of the strain in the polymeric network and the release of water from the material structure (Risbud and Bhat, 2001). The mechanical integrity of the hydrogels indicated that the modulus increased as the degree of theoretical cross-links increased (Table 2), demonstrating that the network became more resistant to deformation (Segura et al., 2005). Values obtained in this study are in agreement with values reported for nucleus 
pulposus in the literature. A modulus of $5.39 \pm 2.56 \mathrm{kPa}$ for the native human nucleus pulposus (Cloyd et al., 2007) has been reported against a modulus comprised between $2.4 \pm 0.12$ and $10.3 \pm 0.40 \mathrm{kPa}$.

A significant constraint in the design of scaffolds for tissue engineering applications is that the porosity of the scaffold allows only a limited diffusion of oxygen and nutrients to the interior of the construct and metabolic waste products cannot be removed efficiently (Lee et al., 2007).

rMSC activity was observed after 1 and 7-day seeding independent of the cross-linker concentration . A decrease in activity was observed after 7 days of culture whereas the number of cells increased (Fig. 7). A confluent cell layer was noted by microscopy on the tissue plastic control similar to that seen in the hydrogel group. This phenomenon explains the decrease in the activity, with cells ceasing to proliferate. The homogenous cell distribution between the different cross-linked hydrogels confirmed a homogenous seeding pattern. This homogenous distribution is desirable in a tissue engineering scaffold. Good cell attachment could be observed using the cell proliferation assay. DNA content reflected cell proliferation, specifically the cell numbers in the hydrogel. No significant difference in DNA content was observed between the cross-linked hydrogels ( 8 and 24mM EDC/ NHS) and the control (tissue culture plastic) after 1 day in culture. No difference in cell attachment rate could be noted between these hydrogels and the control. However, after 24 hours, a lower DNA content was noted for the noncross-linked hydrogel and cross-linked hydrogel with $48 \mathrm{mM}$ EDC/NHS. Lower cell attachment was seen in these hydrogels. The non-cross-linked hydrogel were unstable (Table 1). Consequently, the mesh of this hydrogel was looser, making cell attachment more difficult which explains the lower DNA content. The lowest proliferation level was noted for the $24 \mathrm{mM}$ and $48 \mathrm{mM}$ cross-linked hydrogels after 7 days of culture (Fig. 8). This low proliferation can be associated with the decrease of porosity noted after the increase in cross-linker concentration (for the cross-linked hydrogels; 8,24 and $48 \mathrm{mM}-161 \mu \mathrm{m}$, $93 \mu \mathrm{m}$ and $78 \mu \mathrm{m}$ respectively). Pore size has been shown to control the rate and depth of cellular ingrowth in vivo. When the pore size increases, a higher cell proliferation is noted (Zeltinger et al., 2001). While carrying out this experiment, contraction of the $24 \mathrm{mM}$ and $48 \mathrm{mM}$ crosslinked hydrogels was also noted. Less surface and space was available for the cells for proliferation and attachment. Consequently, the surface/space available for cell growth and proliferation was occupied and cell confluence was reached more quickly for hydrogels cross-linked with $48 \mathrm{mM}$ of EDC/NHS (Fig. 8).

Water content of the disc is an important criteria in the IVD integrity in order for the disc to maintain its mechanical properties (Wuertz et al., 2007). A healthy disc is highly hydrated. During the degeneration process, a loss of water occurs by the deterioration of the ECM composition (Adams and Roughley, 2006; Urban, 2002). No differences were noted between hydration levels in the different cross-linked hydrogels during the physicochemical characterisation studies. The hydrogel cross-linked by $8 \mathrm{mM}$ of EDC showed the most promising results as a NP tissue substitute, based on the maintenance of high swellability, enhanced rMSCs proliferation and improved stability in culture.

Although the origin of the NP cells is still not clear, they are described as chondrocyte-like cells (Roberts et al., 2006). NP cell differentiation is still not fully understood but is under investigation ( $\mathrm{Lu}$ et al., 2008; Sobajima et al., 2007). Hence a more established chondrogenic differentiation medium was used to lead toward a chondrogenic differentiation process. A chondrogenic differentiation into the optimal hydrogel $(1 \mathrm{mM})$ was performed to prove the capability of the hydrogels to support stem cells differentiation into a chondrogenic lineage. Two different pools of cells extracted from two different animals were used in this study. It has been underlined in the literature the interindividual variations of response of bone marrow mesenchymal stem cells to the differentiation stem cells differentiation process (Estes et al., 2010; Siddappa et al., 2007). The same trend for both animals was observed despite the high variation of the standard deviation with statistical differences between the samples. A high level of type II collagen mRNA expression (59.1 \pm 8.93-fold higher compared to monolayer non induced cells) was observed in presence of differentiation medium showing the formation of a neo-matrix. This increase was lower compared to the mRNA expression of type II collagen when cells were cultured in pellet (519.3 \pm 71.04 -fold for pellet culture, 59.1 \pm 8.87 -fold for the hydrogel). We speculate that the lower expression of type II collagen was due to the presence of a type II collagen constituent of the scaffold. It has been shown that the environment of differentiation was an important feature for the differentiation of the rMSCs and the behaviour of the cells (Sundelacruz and Kaplan, 2009). A regulation of the production of type II collagen occurred during the differentiation process. However, neo-matrix of type II collagen was produced. Type I collagen mRNA expression was maintained low when cells were cultured into the hydrogel in presence and absence of differentiation medium as for the culture in pellet. However, despite a high type II collagen expression (54.1 \pm 8.93 -fold higher) when cells were cultured in monolayer, type I collagen expression was noted as high (11.3 \pm 2.92 -fold higher) indicating the formation of a fibro-cartilage rather a hyaline cartilage (Pelttari et al., 2008). Furthermore, a low aggrecan mRNA level was observed whereas a significant increase was noted after culture into the hydrogel. A 5-fold higher expression of proteoglycans into the hydrogel was observed $(84.8 \pm 5.54$ after culture within the hydrogel, $16.8 \pm 4.4$ after culture in pellet) indicating that the hydrogel enhances the production of proteoglycans. This phenomenon can be attributed to the presence of HA (Tang and Spector, 2007) and to the three dimensional structure which promotes the differentiation of the stem cells into chondrocyte-like cells (Gaissmaier et al., 2005). The structure and composition of the hydrogel present allows for mesenchymal stem cells to differentiate into a chondrogenic lineage as shown in this study as indicated 
by the high level of type II collagen and aggrecan mRNA expression. This high expression of aggrecan into the hydrogel in presence of differentiation medium and the capacity of the hydrogel to support the chondrogenic differentiation is promising for the use of this hydrogel for NP cell differentiation. The structure and composition of the hydrogel present allows for mesenchymal stem cells to differentiate into a chondrogenic lineage as shown in this study as indicated by the high level of type II collagen and aggrecan mRNA expression. This high expression of aggrecan into the hydrogel in presence of differentiation medium and the capacity of the hydrogel to support the chondrogenic differentiation is promising for the use of this hydrogel for NP cells differentiation.

\section{Conclusion}

With an overall goal of repairing the NP of degenerated IVDs, the specific aim of this study focused on enhancing the properties of a type II collagen/HA hydrogel via crosslinking with EDC/NHS in order to develop a stable biomimetic hydrogel carrier suitable for supporting rMSC growth and proliferation.

Based on mechanical and chemical analysis, the $48 \mathrm{mM}$ EDC/NHS cross-linked hydrogel demonstrated the most resistance to degradation and the highest elastic modulus. However, independent of the concentration of cross-linker used, all the hydrogels showed porosity sufficient for cell proliferation, a high resistance to collagenase degradation, a high elastic modulus and adequate support of cell growth, proliferation and differentiation into a chondrogenic lineage.

The growth and proliferation of cells was a critical criteria used to determine the optimal properties of the EDC/NHS cross-linked collagen type II/HA hydrogel required for cell seeding. The hydrogel cross-linked with the lower concentration of EDC $(8 \mathrm{mM})$ presents optimal swellability properties, cell proliferation and improved integrity during culture of this hydrogel. Consequently, this hydrogel seems a good candidate for a potential therapeutic target to the regeneration of the NP.

The next step in this research is to determine the association of this hydrogel in a co-culture system of NP cells and MSCs in order observe a potential differentiation into a NP cell-like lineage of MSCs (Richardson et al., 2008; Richardson et al., 2006; Risbud et al., 2004) and subsequently an in vivo study in order to investigate the stem cell fate in vivo within this hydrogel.

\section{Acknowledgment}

This study was financially supported by a grant from the Science Foundation of Ireland, Research Frontiers Programme (07/RFP/ENMF482)

\section{References}

Adams MA, Roughley PJ (2006) What is intervertebral disc degeneration, and what causes it? Spine 31: 21512161.
Alini M, Li W, Markovic P, Aebi M, Spiro RC, Roughley PJ (2003) The potential and limitations of a cellseeded collagen/hyaluronan scaffold to engineer an intervertebral disc-like matrix. Spine 28: 446-454.

Andhare RA, Takahashi N, Knudson W, Knudson CB (2009) Hyaluronan promotes the chondrocyte response to BMP-7. Osteoarthritis Cartilage 17: 892-902.

Baer AE, Wang JY, Kraus VB, Setton LA (2001) Collagen gene expression and mechanical properties of intervertebral disc cell-alginate cultures. J Orthop Res 19: 2-10.

Barnes CP, Pemble CW, Brand DD, Simpson DG, Bowlin GL (2007) Cross-linking electrospun type II collagen tissue engineering scaffolds with carbodiimide in ethanol. Tissue Eng 13: 1593-1605.

Bonnet F, Dunham DG, Hardingham TE (1985) Structure and interactions of cartilage proteoglycan binding region and link protein. Biochem J 228: 77-85.

Cao H, Xu SY (2008) EDC/NHS-crosslinked type II collagen-chondroitin sulfate scaffold: characterization and in vitro evaluation. J Mater Sci Mater Med 19: 567-575.

Cassinelli EH, Hall RA, Kang JD (2001) Biochemistry of intervertebral disc degeneration and the potential for gene therapy applications. Spine J 1: 205-214.

Charulatha V, Rajaram A (2003) Influence of different crosslinking treatments on the physical properties of collagen membranes. Biomaterials 24: 759-767.

Chiba K, Andersson GB, Masuda K, Momohara S, Williams JM, Thonar EJ (1998) A new culture system to study the metabolism of the intervertebral disc in vitro. Spine 23: 1821-1827..

Chung SA, Wei AQ, Connor DE, Webb GC, Molloy T, Pajic M, Diwan AD (2007) Nucleus pulposus cellular longevity by telomerase gene therapy. Spine 32: 11881196.

Cloyd JM, Malhotra NR, Weng L, Chen W, Mauck RL, Elliott DM (2007) Material properties in unconfined compression of human nucleus pulposus, injectable hyaluronic acid-based hydrogels and tissue engineering scaffolds. Eur Spine J 16: 1892-1898.

Colombini A, Lombardi G, Corsi MM, Banfi G (2008) Pathophysiology of the human intervertebral disc. Int $\mathbf{J}$ Biochem Cell Biol 40: 837-842.

Estes BT, Diekman BO, Gimble JM, Guilak F (2010) Isolation of adipose-derived stem cells and their induction to a chondrogenic phenotype. Nat Protoc 5: 1294-1311.

Eyre DR, Matsui Y, Wu JJ (2002) Collagen polymorphisms of the intervertebral disc. Biochem Soc Trans 30: 844-848.

Fritz JM, Cleland JA, Speckman M, Brennan GP, Hunter SJ (2008) Physical therapy for acute low back pain: associations with subsequent healthcare costs. Spine 33: 1800-1805.

Frymoyer JW, Cats-Baril WL (1991) An overview of the incidences and costs of low back pain. Orthop Clin North Am 22: 263-271.

Gaissmaier C, Fritz J, Krackhardt T, Flesch I, Aicher WK, Ashammakhi N (2005) Effect of human platelet supernatant on proliferation and matrix synthesis of human articular chondrocytes in monolayer and three-dimensional alginate cultures. Biomaterials 26: 1953-1960. 
Garcia Y, Collighan R, Griffin M, Pandit A (2007) Assessment of cell viability in a three-dimensional enzymatically cross-linked collagen scaffold. J Mater Sci Mater Med 18: 1991-2001.

Gratzer PF, Lee JM (2001) Control of $\mathrm{pH}$ alters the type of cross-linking produced by 1-ethyl-3-(3dimethylaminopropyl)-carbodiimide (EDC) treatment of acellular matrix vascular grafts. J Biomed Mater Res 58: 172-179.

Halloran DO, Grad S, Stoddart M, Dockery P, Alini M, Pandit AS (2008) An injectable cross-linked scaffold for nucleus pulposus regeneration. Biomaterials 29: 438447.

Hardingham TE (1979) The role of link-protein in the structure of cartilage proteoglycan aggregates. Biochem J 177: $237-247$.

Horner HA, Roberts S, Bielby RC, Menage J, Evans H, Urban JP (2002) Cells from different regions of the intervertebral disc: effect of culture system on matrix expression and cell phenotype. Spine 27: 1018-1028.

Humzah MD, Soames RW (1988) Human intervertebral disc: structure and function. Anat Rec 220: 337-356.

Hunter CJ, Matyas JR, Duncan NA (2003) The notochordal cell in the nucleus pulposus: a review in the context of tissue engineering. Tissue Eng 9: 667-677.

Kawasaki K, Ochi M, Uchio Y, Adachi N, Matsusaki M (1999) Hyaluronic acid enhances proliferation and chondroitin sulfate synthesis in cultured chondrocytes embedded in collagen gels. J Cell Physiol 179: 142-148. Lecroisey A, Keil B (1979) Differences in the degradation of native collagen by two microbial collagenases. Biochem J 179: 53-58.

Lee M, Wu BM, Dunn JCY (2007) Effect of scaffold architecture and pore size on smooth muscle cell growth. J Biomed Mater Res A 87: 1010-1016.

Lu ZF, Doulabi BZ, Wuisman PI, Bank RA, Helder MN (2008) Influence of collagen type II and nucleus pulposus cells on aggregation and differentiation of adipose tissue-derived stem cells. J Cell Mol Med 12: 2812-2822.

Maleki A, Kjoniksen AL, Nystrom B (2007) Characterization of the chemical degradation of hyaluronic acid during chemical gelation in the presence of different cross-linker agents. Carbohydr Res 342: 2776-2792.

Nakajima N, Ikada Y (1995) Mechanism of amide formation by carbodiimide for bioconjugation in aqueous media. Bioconjug Chem 6: 123-130.

Nesti LJ, Li WJ, Shanti RM, Jiang YJ, Jackson W, Freedman BA, Kuklo TR, Giuliani JR, Tuan RS (2008) Intervertebral disc tissue engineering using a novel hyaluronic acid-nanofibrous scaffold (HANFS) amalgam. Tissue Eng Part A 14: 1527-1537.

Neuhuber B, Gallo G, Howard L, Kostura L, Mackay A, Fischer I (2004) Reevaluation of in vitro differentiation protocols for bone marrow stromal cells: disruption of actin cytoskeleton induces rapid morphological changes and mimics neuronal phenotype. J Neurosci Res 77: 192-204.

O'Halloran D, Collighan RJ, Griffin M, Pandit AS (2006) Characterization of a microbial transglutaminase cross-linked type II collagen scaffold. Tissue Eng 12: 14671474.
O'Halloran D, Pandit A (2007) Injectable Scaffold Approach Towards Regenerating the Nucleus Pulposus, PhD Thesis. Department of Mechanical and Biomedical Engineering, National University of Ireland Galway, Galway, pp 233.

Ovcharenko D, Jarvis R, Hunicke-Smith S, Kelnar K, Brown D (2005) High-throughput RNAi screening in vitro: from cell lines to primary cells. RNA 11: 985-993.

Patel VR, Amiji MM (1996) Preparation and characterization of freeze-dried chitosan-poly(ethylene oxide) hydrogels for site-specific antibiotic delivery in the stomach. Pharm Res 13: 588-593.

Pelttari K, Steck E, Richter W (2008) The use of mesenchymal stem cells for chondrogenesis. Injury 39 Suppl 1: S58-65.

Perie D, Korda D, Iatridis JC (2005) Confined compression experiments on bovine nucleus pulposus and annulus fibrosus: sensitivity of the experiment in the determination of compressive modulus and hydraulic permeability. J Biomech 38: 2164-2171.

Pieper JS, van der Kraan PM, Hafmans T, Kamp J, Buma P, van Susante JL, van den Berg WB, Veerkamp JH, van Kuppevelt TH (2002) Crosslinked type II collagen matrices: preparation, characterization, and potential for cartilage engineering. Biomaterials 23: 3183-3192.

Richardson SM, Hughes N, Hunt JA, Freemont AJ, Hoyland JA (2008) Human mesenchymal stem cell differentiation to NP-like cells in chitosanglycerophosphate hydrogels. Biomaterials 29: 85-93.

Richardson SM, Walker RV, Parker S, Rhodes NP, Hunt JA, Freemont AJ, Hoyland JA (2006) Intervertebral disc cell-mediated mesenchymal stem cell differentiation. Stem Cells 24: 707-716.

Risbud MV, Albert TJ, Guttapalli A, Vresilovic EJ, Hillibrand AS, Vaccaro AR, Shapiro IM (2004) Differentiation of mesenchymal stem cells towards a nucleus pulposus-like phenotype in vitro: implications for cell-based transplantation therapy. Spine 29: 2627-2632.

Risbud MV, Bhat SV (2001) Properties of polyvinyl pyrrolidone/beta-chitosan hydrogel membranes and their biocompatibility evaluation by haemorheological method. J Mater Sci Mater Med 12: 75-79.

Roberts S, Evans H, Trivedi J, Menage J (2006) Histology and pathology of the human intervertebral disc. J Bone Joint Surg Am 88 Suppl 2: 10-14.

Roberts S, Menage J, Duance V, Wotton S, Ayad S (1991) 1991 Volvo Award in basic sciences. Collagen types around the cells of the intervertebral disc and cartilage end plate: an immunolocalization study. Spine 16: 10301038.

Rooney P, Kumar S (1993) Inverse relationship between hyaluronan and collagens in development and angiogenesis. Differentiation 54: 1-9.

Roughley P, Hoemann C, DesRosiers E, Mwale F, Antoniou J, Alini M (2006) The potential of chitosan-based gels containing intervertebral disc cells for nucleus pulposus supplementation. Biomaterials 27: 388-396.

Saito H, Murabayashi S, Mitamura Y, Taguchi T (2008) Characterization of alkali-treated collagen gels prepared by different crosslinkers. J Mater Sci Mater Med 19: 1297 1305. 
Sakai D, Mochida J, Iwashina T, Watanabe T, Suyama K, Ando K, Hotta T (2006) Atelocollagen for culture of human nucleus pulposus cells forming nucleus pulposuslike tissue in vitro: influence on the proliferation and proteoglycan production of HNPSV-1 cells. Biomaterials 27: 346-353.

Segura T, Anderson BC, Chung PH, Webber RE, Shull KR, Shea LD (2005) Crosslinked hyaluronic acid hydrogels: a strategy to functionalize and pattern. Biomaterials 26: 359-371.

Siddappa R, Licht R, van Blitterswijk C, de Boer J (2007) Donor variation and loss of multipotency during in vitro expansion of human mesenchymal stem cells for bone tissue engineering. J Orthop Res 25: 1029-1041.

Sobajima S, Vadala G, Shimer A, Kim JS, Gilbertson LG, Kang JD (2007) Feasibility of a stem cell therapy for intervertebral disc degeneration. Spine J 8: 888-896.

Stern S, Lindenhayn K, Schultz O, Perka C (2000) Cultivation of porcine cells from the nucleus pulposus in a fibrin/hyaluronic acid matrix. Acta Orthop Scand71: 496502.

Strine TW, Hootman JM (2007) US national prevalence and correlates of low back and neck pain among adults. Arthritis Rheum 57: 656-665.

Sundelacruz S, Kaplan DL (2009) Stem cell- and scaffold-based tissue engineering approaches to osteochondral regenerative medicine. Semin Cell Dev Biol 20: 646-655.

Taguchi T, Ikoma T, Tanaka J (2002) An improved method to prepare hyaluronic acid and type II collagen composite matrices. J Biomed Mater Res 61: 330-336.
Tang S, Spector M (2007) Incorporation of hyaluronic acid into collagen scaffolds for the control of chondrocytemediated contraction and chondrogenesis. Biomed Mater 2: S135-141.

Tang S, Vickers SM, Hsu HP, Spector M (2006) Fabrication and characterization of porous hyaluronic acidcollagen composite scaffolds. J Biomed Mater Res A 82: 323-335.

Tengblad A, Pearce RH, Grimmer BJ (1984) Demonstration of link protein in proteoglycan aggregates from human intervertebral disc. Biochem J, 222: 85-92.

Urban JP (2002) The role of the physicochemical environment in determining disc cell behaviour. Biochem Soc Trans 30: 858-864.

Urban JP, Roberts S (2003) Degeneration of the intervertebral disc. Arthritis Res Ther 5: 120-130.

Wan Y, Feng G, Shen FH, Laurencin CT, Li X (2008) Biphasic scaffold for annulus fibrosus tissue regeneration. Biomaterials 29: 643-652.

Wuertz K, Urban JP, Klasen J, Ignatius A, Wilke HJ, Claes L, Neidlinger-Wilke C (2007) Influence of extracellular osmolarity and mechanical stimulation on gene expression of intervertebral disc cells. J Orthop Res 25: 1513-1522.

Zeltinger J, Sherwood JK, Graham DA, Mueller R, Griffith LG (2001) Effect of pore size and void fraction on cellular adhesion, proliferation, and matrix deposition. Tissue Eng 7 :557-572.

Zhu W, Iatridis JC, Hlibczuk V, Ratcliffe A, Mow VC (1996) Determination of collagen-proteoglycan interactions in vitro. J Biomech 29: 773-783. 